Disponível em:

http://editora.unoesc.edu.br/index.php/race

RACE, Joaçaba, v. 17, n. 1, p. 313-332, jan./abr. 2018

\title{
OS DOADORES E POTENCIAIS DOADORES DE ENTIDADES CARENTES: QUEM SÃO ELES?
}

\author{
Donors and Potential Donors to Charities: Who are They?
}

Anna Cecília Chaves Gomes

E-mail: anna.gomes@ifpb.edu.br

Doutora e Mestre em Gestão Organizacional pela Universidade Federal do Rio Grande do Norte; Professora efetiva de Administração Financeira no Instituto Federal de Educação Tecnológica da Paraíba de Guarabira. Endereço para contato: PB-057, 2, Nordeste, 58200-000, Guarabira, Paraíba, Brasil.

Bruna Lyra Alves de Almeida

E-mail: bruna.alves@ifpb.edu.br Mestre em Administração pela Universidade Federal da Paraíba; MBA em Gestão de Pessoas pela MRH/Fundação Getúlio Vargas; Professora efetiva no Instituto Federal de Educação, Ciência e Tecnologia da Paraíba de Guarabira.

Andreza Raielly Alexandre de Lima E-mail: andrezaraielly2015@gmail.com

Graduada em Gestão Comercial pelo Instituto Federal de Educação, Ciência e Tecnologia da Paraíba de Guarabira; Diretora de Projetos da Empresa Junior IF Consult.

Anannda Rios dos Santos

E-mail: anannda@recrutaja.com.br

Graduada em Gestão Comercial pelo Instituto Federal de Educação, Ciência e Tecnologia da Paraíba de Guarabira; Fundadora e CEO da empresa Recruta, na qual trabalha no seguimento de recrutamento e seleção de profissionais.

Jailson Jerônimo dos Santos

E-mail: jailsonsud@hotmail.com

Graduando em Gestão Comercial no Instituto Federal de Educação, Ciência e Tecnologia da Paraíba de Guarabira; Técnico em Segurança no Trabalho no Instituto Federal de Educação, Ciência e Tecnologia da Paraíba de Guarabira.

Cleison da Silva Nascimento

E-mail: cleisoninfo2013@gmail.com

Graduado em Gestão Comercial pelo Instituto Federal de Educação, Ciência e Tecnologia da Paraíba de Guarabira; Auxiliar de informática na Escola de Ensino Fundamental e Médio Engenheira Márcia Guedes Alcoforado de Carvalho. 


\section{Alaine Caroline Cruz Freire \\ E-mail: alainefreire0@gmail.com}

Graduada em Gestão Comercial pelo Instituto Federal de Educação, Ciência e Tecnologia da Paraíba de Guarabira; Pesquisadora da base Gestão, Operações e Métodos do Instituto Federal de Educação, Ciência e Tecnologia da Paraíba de Guarabira.

Tatiana Losano de Abreu

E-mail: tatiana.abreu@ifpb.edu.br

Mestre em Economia Aplicada pela Universidade Federal da Paraíba; Graduada em Ciências Econômicas pela Universidade Federal da Paraíba de Guarabira; Professora efetiva no Instituto Federal de Educação, Ciência e Tecnologia da Paraíba de Guarabira. 


\section{Resumo}

O objetivo com o presente estudo foi identificar o perfil dos atores da sociedade civil que contribuem e também são potenciais doadores de entidades carentes em geral, com destaque na doação de alimentos, na Cidade de Guarabira, PB. Para tanto, foi realizada uma pesquisa de caráter exploratório-descritiva, com abordagem quantitativa. A partir de uma amostra de 384 entrevistados, evidenciou-se que uma parcela da população já realiza doações e existe um percentual considerável de pessoas interessadas em realizá-las também. A pesquisa mostrou que a maioria do público que pratica doações é formado por homens, porém, sobre quem não doa, as mulheres se mostraram como potenciais doadoras. Homens e mulheres jovens, entre 20 e 29 anos, preferem doar aquilo que já possuem e não se mostram abertos a comprar alimentos para doar. Pessoas viúvas compõem um grupo ativo no auxílio às entidades carentes, mas não realizam suas doações em forma de alimentos, seguidas das pessoas divorciadas. Pessoas com a faixa de renda baixa mostraram ser um grupo de potenciais doadores por interesse em doar, já as com faixa de renda maior apresentaram interesse maior em comprar para doar. Percebeuse que, de modo geral, há interesse dos entrevistados em realizar ações que colaborem com entidades sem fins lucrativos da Cidade de Guarabira, PB, sobretudo em relação à doação de alimentos. Para tanto, faz-se necessário voltar para ações de marketing social junto aos doadores e potenciais doadores, para melhor desenvolver estratégias para evitar a perda e o desperdício de alimentos e otimizar o processo de doação.

Palavras-chave: Entidades carentes. Pesquisa de mercado. Doações.

\section{Abstract}

The objective of the present study was to identify the profile of civil society actors who contribute and are also potential donors of poor entities in general, with a focus on food donation, in the City of Guarabira, PB. For that, a descriptive exploratory research was conducted, with a quantitative approach. From a sample of 384 interviewees, it was shown that a portion of the population already makes donations and there is a considerable percentage of people interested in accomplishing them as well. Research has shown that the majority of the donating public is men, but women who donate do not donate, as potential donors. Young men and women between the ages of 20 and 29 prefer to donate what they already have and are not open to buying food to donate. Widowed people make up an active group in aid to the needy entities, but do not make their donations in the form of food, followed by the divorced people. People with the low income bracket have shown to be a group of potential donors for interest in donating, while those with higher income brackets have shown greater interest in buying to donate. It was noticed that, in general, the interviewees are interested in carrying out actions that collaborate with non-profit entities in the City of Guarabira, $P B$, especially in relation to food donation. To do so, it is necessary to turn to social marketing actions, together with donors 
and potential donors, to better develop strategies to avoid loss and waste of food and optimize the donation process.

Keywords: Needy entities. Market research. Donations.

\section{INTRODUÇÃO}

Sabe-se que as organizações não governamentais necessitam de informações socioeconômicas de mercado para uma efetiva gestão administrativa de seus recursos. As relações entre as organizações sem fins lucrativos e os atores sociais com os quais elas articulam são "fator de grande importância para a gestão no campo social, uma vez que a sobrevivência de tais organizações depende fundamentalmente das interações que estabelecem.” (THIBES; MORETTO NETO, 2011, p. 134).

Pesquisas sobre a gestão das organizações não governamentais vêm ganhando atenção dentro do mundo acadêmico, ao passo que cresce o número de instituições fora dele, sobretudo em razão da descentralização na gestão de políticas públicas e da redução dos financiamentos de agências internacionais. Ademais, essas instituições passam por mudanças na sua gestão organizacional em prol de autonomia e sustentabilidade, seja por meio de atividades comerciais, seja por parcerias com o setor privado ou com o Estado (ROESCH, 2002).

A realidade mostra que muitos são os desafios enfrentados pelas organizações sem fins lucrativos para alcançarem tal sustentabilidade e autonomia, principalmente em relação à identificação de um modelo gerencial eficiente que alinhe as demandas sociais e uma sustentabilidade efetiva (VIDAL; MENEZES, 2004). As ONGs fazem parte de um ambiente no qual precisam se tornar capazes de prospectar recursos por meio de estratégias voltadas para a manutenção e o avanço das suas atividades e projeto sociais (OLIVEIRA; BORGES, 2013). Portanto, a captação de recursos se torna elemento fundamental na gestão dessas organizações, pois os programas e ações sociais, culturais e ambientais dependem deles (SANTOS; SILVA, 2012).

Assim, as estratégias de gestão necessárias envolvem o todo da organização, não apenas o que diz respeito aos recursos financeiros, mas também, segundo Santos e Silva (2012), estratégias de gestão efetivas sobre a gestão das pessoas, como voluntários e beneficiários, e manutenção de uma boa imagem perante a sua comunidade. “O desafio, portanto, é encontrar formas de gestão que se adequem às particularidades destas organizações, sua história, seu papel na sociedade.” (ROESCH, 2002, p. 2).

Muitos são os atores que estabelecem relações com as instituições do Terceiro Setor, a exemplo das organizações patrocinadoras, das instituições realizadoras e 
idealizadoras, dos órgãos colaboradores, das parcerias realizadas com instituições de fomento e órgãos estatais e dos trabalhadores voluntários (TONDOLO, 2013). Destaca-se, ainda, o envolvimento com indivíduos e núcleos familiares. Snipes e Oswald (2010) destacam que a contribuição média dos membros familiares às organizações sem fins lucrativos tem crescido nos anos recentes, e em contraponto, o número de pessoas que efetivamente contribui caiu. Portanto, neste estudo, questiona-se: quem são esses indivíduos doadores? Qual o nível de renda deles? As mulheres possuem maior propensão a doar do que os homens?

É notório que as doações de alimentos e de dinheiro são dois tipos de contribuições muito requisitadas pelas ONGs, contudo, a partir das pesquisas bibliográficas, evidenciaram-se poucos estudos com foco na doação de alimentos, e tampouco sobre o público-alvo de doadores que essas organizações precisam abranger. Entende-se que essas informações servem de subsídio, como fonte de pesquisa de mercado, para uma gestão mais eficiente dos recursos e estratégias utilizadas pelas ONGs de modo a aproximá-las da comunidade, da qual elas se fazem tão dependentes. Além do mais, faltam estudos publicados sobre as práticas de gestão das ONGs, sobretudo no Brasil, e o fato dessas organizações possuírem diferentes objetivos dificulta a conceituação de seus papéis e a realização de pesquisas comparativas empíricas (ROESCH, 2002).

Portanto, apresentam-se neste artigo os resultados de uma pesquisa, realizada na Cidade de Guarabira, PB em que se teve como objetivo central identificar o perfil dos atores da sociedade civil que contribuem e também são potenciais doadores de entidades carentes em geral, com destaque na doação de alimentos. Vale destacar que, no presente estudo, considera-se os termos “organizações sem fins lucrativos” e “entidades carentes” como sinônimos, sendo o segundo termo mais usual pela população em geral.

\section{O TERCEIRO SETOR, AS ONGS E OS DOADORES DE} ALIMENTOS

As ONGs fazem parte do terceiro setor, que abrange todo tipo de organização social que não visa lucro. Nas décadas de 1980 e 1990 passou-se a definir grupos de organizações sem fins lucrativos como terceiro setor, como: associações recreativas, assistencialistas, ambientalistas, educacionais, religiosas, fundações e institutos (CALIXTO, 2009; BITENCOURT et al., 2007 apud TONDOLO, 2013). Roesch (2002) entende que o terceiro setor diz respeito a organizações de diferentes tipos e que não há consenso sobre seu significado. 
No caso das organizações não governamentais (ONGs), surgiram nos EUA, no período pós-Segunda Guerra (ASSOCIAÇÃO BRASILEIRA DAS ONGS, 2005), mas foi a partir da década de 1980 que seu nome foi utilizado de forma abrangente como sinônimo para qualquer tipo de organização sem fins lucrativos (McKINSEY; COMPANY, 2001 apud BORBA et al., 2012), como acontece ainda hoje.

As ONGs surgem como resposta à acentuada diferença de classes sociais decorrente do sistema capitalista, intensificada pelo fenômeno da globalização e das políticas neoliberais ineficientes e incapazes de suprir as demandas sociais de forma justa e igualitária. Portanto, o terceiro setor se caracteriza por modelos de organizações voltadas para preencher os espaços ou lacunas sociais, nos quais nem o Estado, nem o capital chegam.

As ONGs integram um mercado social intitulado 'Terceiro Setor' que ocupa espaços não preenchidos pelo Estado (Primeiro Setor) e pela atuação do setor privado, que enfatiza a comercialização de bens e serviços, a fim de atender a expectativas de um mercado comercial (Segundo Setor) (TACHIZAWA apud VIDAL; MENEZES, 2004, p. 2).

No Brasil, as ONGs surgiram na década de 1970, e em razão da recessão do apoio econômico de agências financiadoras internacionais, muitas tiveram que buscar outras formas de se manterem sustentáveis, por intermédio, principalmente, de organismos privados ou estatais (ROESCH, 2002). Nesse sentido, as doações de caridade têm se tornado uma importante fonte de financiamento para elas (JACKLEVIC, 2000 apud SNIPES; OSWALD, 2010). Contudo, a viabilidade das doações filantrópicas está cada vez mais crítica, vista em longo prazo (SNIPES; OSWALD, 2010).

No caso das doações de alimentos, não é diferente. Evidenciam-se diversos fatores críticos representados, principalmente, pelos hábitos frequentes de desperdício e perda de alimentos pela população participante da cadeia de produção de alimentos, seja pela indústria de insumos e equipamentos, agricultores, indústria de processamento, distribuidores, seja por representantes do Estado, incluindo os consumidores. Peixoto e Pinto (2016) chamam atenção para os impactos do desperdício de alimentos que geram pesados danos à sociedade como um todo, sobretudo no que diz respeito às consequências econômicas; a partir da relação da redução da oferta e aumento de preços, as perdas estimadas giram em torno de US\$ 750 bilhões, anualmente.

Embora as condições de doação tenham mudado completamente nos últimos séculos, a doação de alimentos, designada para evitar o desperdício, muitas vezes en- 
frenta barreiras e resistência (SCHNEIDER, 2013). No caso do Brasil, entre barreiras culturais, como hábitos de consumo consciente, apresentam-se também barreiras legais, pois existe a possibilidade de doadores de alimentos serem responsabilizados por problemas causados à saúde do donatário. O doador, assim, assumiria o risco de pagar indenização pelo dano sofrido pelo donatário ao doar alimentos. "Por essa razão, é fundamental que a legislação explicitamente restrinja a responsabilidade civil do doador a casos de dolo, nos termos do art. 392 do Código Civil” (PEIXOTO; PINTO, 2016), o que favoreceria, assim, o hábito de doar em lugar do descarte de alimentos.

No âmbito dos consumidores, os custos econômicos relacionados ao desperdício de alimentos podem ser aumentados pelo "planejamento inadequado do consumo e a compreensão incorreta das datas de validade, em combinação com a atitude descuidada em relação ao preparo e à conservação dos alimentos.” Muitas iniciativas de doação têm sido tomadas pela sociedade visando ao combate ao descarte de alimentos, contudo, com abrangência muito limitada e resultados pouco significativos (PEIXOTO; PINTO, 2016, p. 4).

Considera-se fundamental que as organizações sem fins lucrativos adotem práticas de gestão que estimulem hábitos de combate ao desperdício de alimentos associado às doações, incluindo o estímulo do marketing social para a incorporação do senso de solidariedade e generosidade, que segundo Peixoto e Pinto (2016), são essas condutas fraternas que contribuem para a redução das consequências da fome. Assim, para aumentar o quantitativo das doações de alimentos, as organizações não governamentais precisam buscar meios de conhecer melhor o público que faz doações e quais as variáveis que podem influenciar o processo de decisão de doar.

Alguns fatores influenciam o comportamento dos indivíduos na decisão de doar, entre os quais destacam-se: assistência anterior ou experiência com as organizações sem fins lucrativos; escopo dos serviços prestados pela organização; consciência sobre a existência da organização e dos seus serviços; reputação da organização; anúncios por parte da organização sobre as doações necessárias (SNIPES; OSWALD, 2010); entre outros.

Entender as doações à caridade é um elemento crucial para atrair e reter doadores, sendo que os preditores tradicionais para tais se baseiam em comportamentos anteriores e aspectos sociodemográficos (VERHAERT; POEL, 2011). Cresce o número de evidências sugerindo que o comportamento de homens e mulheres no que se refere a doações é diferenciado (SNIPES; OSWALD, 2010). Há muito tempo, pesquisadores das ciências sociais e comportamentais têm corroborado estereótipos que afirmam que homens são mais individualistas e menos propensos a contribuir com 
causas de caridade, enquanto mulheres apresentariam uma orientação mais social, logo, mais propensa a contribuir (ECKEL; GROSSMAN, 2008). Estudos de diferenças comportamentais para fins monetários entre gêneros têm resultado em observações divergentes. Nowell e Tinkler (1994) afirmam que as mulheres contribuem mais. Eckel e Grossman (2008) indicam que quando se envolve a questão da situação monetária não existe diferença significativa entre gêneros, contudo, quando este é retirado, as mulheres teriam uma orientação menos individualista. Contrariamente a essas opiniões, observa-se que nos experimentos que analisam bens públicos, como o de Brown-Kruse e Hummels (1993), houve evidências para considerar os homens como maiores contribuintes para o grupo.

Embora menos frequentes, outros aspectos demográficos também têm mostrado aspectos que afetam a predisposição a realizar doações, como, por exemplo, a idade, o estado civil e a renda (SNIPES; OSWALD, 2010).

A seguir, estão descritos os procedimentos metodológicos que conduziram à investigação sobre o público-alvo de doares e os fatores que influenciam seu processo de decisão de doar.

\section{METODOLOGIA}

O presente estudo caracteriza-se, quanto à sua finalidade, como exploratório-descritivo, dado que se procura proporcionar familiaridade com o tema, visando torná-lo explícito (exploratório), tratando ainda de descrever as características de uma população em análise (descritivo) (SILVA; MENEZES, 2005). Seria ainda quantitativo no que se refere à sua abordagem, dado que traduz, em números, opiniões e informações trabalhando primordialmente com dados passíveis de quantificação (SILVA; MENEZES, 2005).

Para se realizar o cálculo amostral, inicialmente se obteve a estimativa populacional do Instituto Brasileiro de Geografia e Estatísticas (IBGE) para o total de residentes na Cidade de Guarabira, PB em 2015 (previsão de 58.162 habitantes), e, em seguida, realizou-se o cálculo amostral de acordo com Santos (2016), para 95\% de confiança e 5\% de erro. A amostra definida foi de 384 pessoas.

A aplicação do questionário ocorreu nos meses de abril e maio de 2016, no Centro de Guarabira, PB, uma vez que este é um bairro essencialmente comercial, concentrando $43 \%$ dos comércios da Cidade e 75\% dos supermercados. Logo, essa região é a maior concentradora de indivíduos envolvidos em decisões de compras de 
suas residências e, consequente, potenciais doadores, segundo informações da Receita Estadual.

Embora existam inúmeros projetos, implementados mundialmente para a doação de alimentos, a literatura científica acerca do tópico é rara (SCHNEIDER, 2013). A análise da predisposição de um indivíduo tornar-se doador de alimentos se torna complexa também na medida em que não necessariamente a doação ocorre unicamente com o desejo de ajudar o próximo, devendo-se analisar também o tema do sentimento negativo observado ao se desperdiçar comida que poderia ter sido utilizada por outros. Considera-se, ainda, que muitos podem não doar por falta de informação. Logo, deve-se observar na análise de possíveis doadores: se o indivíduo costuma auxiliar entidades carentes, se ele gostaria de fazê-lo, se doa alimentos, se gostaria e poderia comprar para doar e se poderia e gostaria de doar alimentos próximos ao vencimento.

A partir desse conjunto de observações, procura-se analisar quem seriam os doadores potenciais e efetivos. Para tal, os dados foram tratados com estatísticas descritivas, testes de médias e correlações. Adotou-se 95\% como confiança exigida dos testes. Entre as ferramentas da estatística descritiva, destacam-se o uso da pirâmide etária, a análise de correlação e o teste de hipótese.

\section{RESULTADOS}

Os entrevistados são, em sua maioria, mulheres (54,7\%), de renda entre um salário mínimo e R \$ 1.500,00 (47,4\%), solteiras ou casadas (41,4\% e 41,7\%, respectivamente) e apresentam idade média de 33 anos (desvio padrão de 12,6). Percebe-se que as mulheres entrevistadas tendem a ganhar menos que os homens, sendo essa diferença estatisticamente significante ( $\mathrm{p}$-valor = 0,000). Como forma de verificar quão os indivíduos em geral estariam dispostos e aptos a se tornarem ou se manterem como doadores das entidades carentes, tem-se a Tabela 1.

Percebe-se que a maioria dos entrevistados ajuda de alguma forma as entidades carentes (50,8\%) e estaria doando alimentos (50\%). De fato, ambos questionamentos estariam relacionados $(\rho=0,666$, p-valor $=0,000)$ de forma moderada, ou seja, pessoas que auxiliam intensamente entidades carentes de forma geral tendem também a auxiliá-las intensamente sob forma de doação de alimentos. Tal resultado pode estar representando que já existe na Cidade uma iniciativa de doação sob forma de alimentos, e não apenas de capital, roupas ou objetos, o que não seria estranho aos indivíduos que a entidade fizesse sua solicitação de doação sob forma de alimentos. 
Tabela 1 - Questionamentos acerca do envolvimento dos indivíduos de Guarabira com o auxílio a entidades carentes

\begin{tabular}{|c|c|c|c|c|c|}
\hline Questão & $\begin{array}{l}\text { Discor- } \\
\text { do total- } \\
\text { mente }\end{array}$ & $\begin{array}{l}\text { Discor- } \\
\text { do }\end{array}$ & $\begin{array}{l}\text { Não sei } \\
\text { afirmar }\end{array}$ & $\begin{array}{l}\text { Concor- } \\
\text { do }\end{array}$ & $\begin{array}{c}\text { Concor- } \\
\text { do total- } \\
\text { mente }\end{array}$ \\
\hline Eu ajudo de alguma forma as entidades carentes & $27,6 \%$ & $8,9 \%$ & $12,8 \%$ & $22,9 \%$ & $27,9 \%$ \\
\hline Eu gostaria de auxiliar entidades carentes & $4,4 \%$ & $2,3 \%$ & $16,1 \%$ & $33,1 \%$ & $44 \%$ \\
\hline Eu costumo doar alimentos a entidades carentes & $26,3 \%$ & $10,7 \%$ & $13 \%$ & $27,3 \%$ & $22,7 \%$ \\
\hline $\begin{array}{l}\text { Eu poderia e gostaria de comprar alimentos } \\
\text { para doar a entidades carentes }\end{array}$ & $6,8 \%$ & $6,5 \%$ & $17,2 \%$ & $35,7 \%$ & $33,9 \%$ \\
\hline $\begin{array}{l}\text { Eu poderia e gostaria de doar alimentos que } \\
\text { venceriam em minha casa a entidades carentes }\end{array}$ & $13,5 \%$ & $6,3 \%$ & $6 \%$ & $36,5 \%$ & $37,8 \%$ \\
\hline
\end{tabular}

Existe espaço para a ampliação do número de doadores, uma vez que 50,8\% ajudam de alguma forma as entidades, contudo, 77,1\% apresentam interesse em realizar doações. Caberia a essas organizações encontrar formas de captar esses indivíduos para ampliar as doações recebidas. Esse resultado reforça a importância de detectar o púbico interessado em doar, pois o marketing social deve atingir toda a parcela da população, de modo a efetivar a ampliação dos doadores.

Quanto à forma da doação dos alimentos, 69,6\% gostariam e poderiam adquirir o produto para doar e 74,3\% afirmam que gostariam e poderiam doar como forma de reduzir o desperdício em suas casas, revelando que os respondentes estariam preocupados com a perda de alimentos que poderiam ser aproveitados por outros, sendo esse segmento de possíveis clientes mais amplo que o anterior. Ainda nesse aspecto, ressalta-se um percentual significativo de 13,5\% de pessoas que não doariam alimentos que venceriam em sua casa de maneira alguma (discordam totalmente). Desse total, a maioria (69,2\%) poderia e gostaria de comprar para doar. Realizando um comparativo entre os indivíduos que discordaram totalmente da ideia de doar alimentos que venceriam e que concordam (em qualquer nível) em comprar para doar, constatou-se que $9,3 \%$ da amostra temem enfaticamente em doar esse tipo de alimento provavelmente com receio de gerar algum mal-estar para as pessoas receptoras, considerando a proximidade do vencimento do alimento.

Observando a influência do gênero (masculino e feminino) em relação ao ato de doar, tem-se que os homens entrevistados demostraram maior prática de realizar doação. Esse resultado contradiz os estudos de Eckel e Grossman (2008) e Nowell e Tinkler (1994), contudo, como foi observado, as mulheres tendem a ganhar significativamente menos do que os homens; pode-se supor que essa diferença de salários tenha influência no resultado apresentado. 
Isolando-se apenas os indivíduos que não auxiliam entidades carentes, tem-se que 45,2\% dos homens apresentariam interesse, percentual menor se comparado com as mulheres (54,8\%). Para fins de marketing social voltado a estimular a continuidade das doações, sugere-se o foco na população masculina, enquanto que, para estimular novas doações, a estratégia deve ser focada no convencimento das mulheres.

Com o objetivo de observar a correlação entre a idade e o ato de doar, destaca-se que pessoas mais velhas são mais propensas a auxiliar de alguma forma as entidades carentes sob as diversas formas ( $\rho=0,149$ e $p$-valor $=0,003)$, inclusive com as doações de alimentos ( $\rho=0,155$, p-valor=0,002). Tal relação, contudo, demonstra-se demasiadamente fraca em ambos os aspectos. Dessa forma, outros enfoques se tornam mais relevantes para a análise proposta aqui.

Visando analisar a relação entre idade e gênero dos doadores atuais e/ou potenciais, assim como sua dimensão em termo de quantidades de habitantes em Guarabira, PB, foram construídas pirâmides etárias envolvendo dados dos doadores (isolando-se apenas pessoas que concordaram com as afirmações em análise) e dados populacionais da Cidade de Guarabira, PB, disponibilizados pelo IBGE (2016). A primeira pirâmide etária apresenta os resultados a partir dos indivíduos que já auxiliam entidades carentes (Gráfico 1), a segunda trata das pessoas que não necessariamente doam, contudo, apresentaram interesse em fazê-lo (Gráfico 2). A terceira (Gráfico 3) isola as pessoas que realizam doações sob forma de alimentos.

Gráfico 1 - Pirâmide etária em relação às respostas do item "Eu ajudo de alguma forma as entidades carentes”

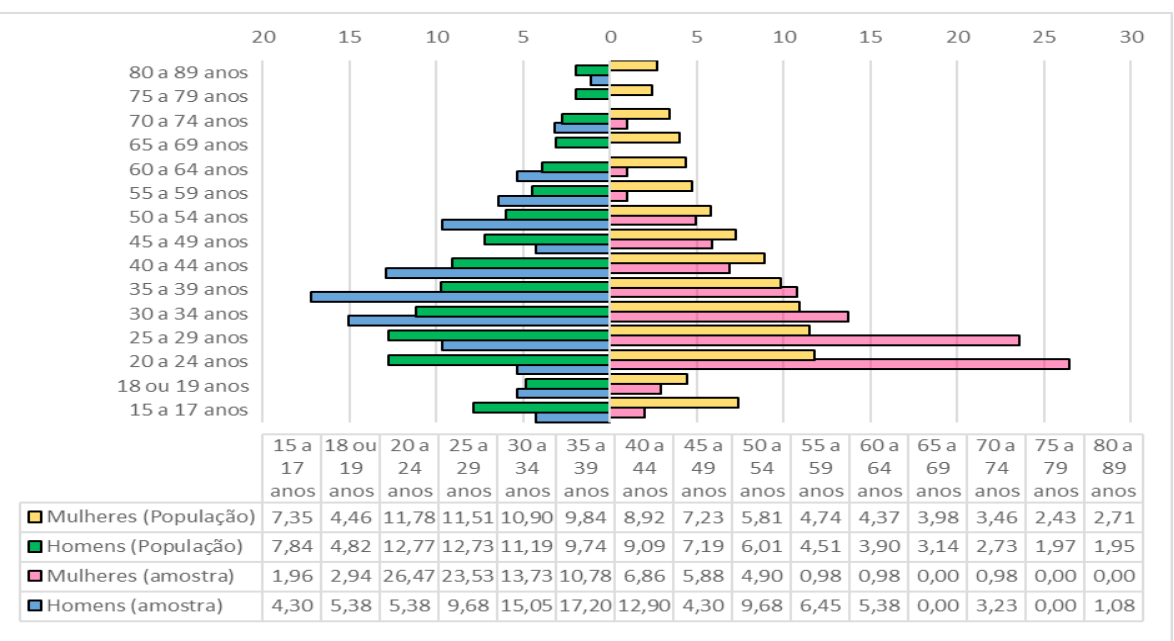

Fonte: os autores. 
Anna Cecília Chaves Gomes et al.

Gráfico 2 - Pirâmide etária em relação às respostas do item "Eu gostaria de auxiliar entidades carentes"

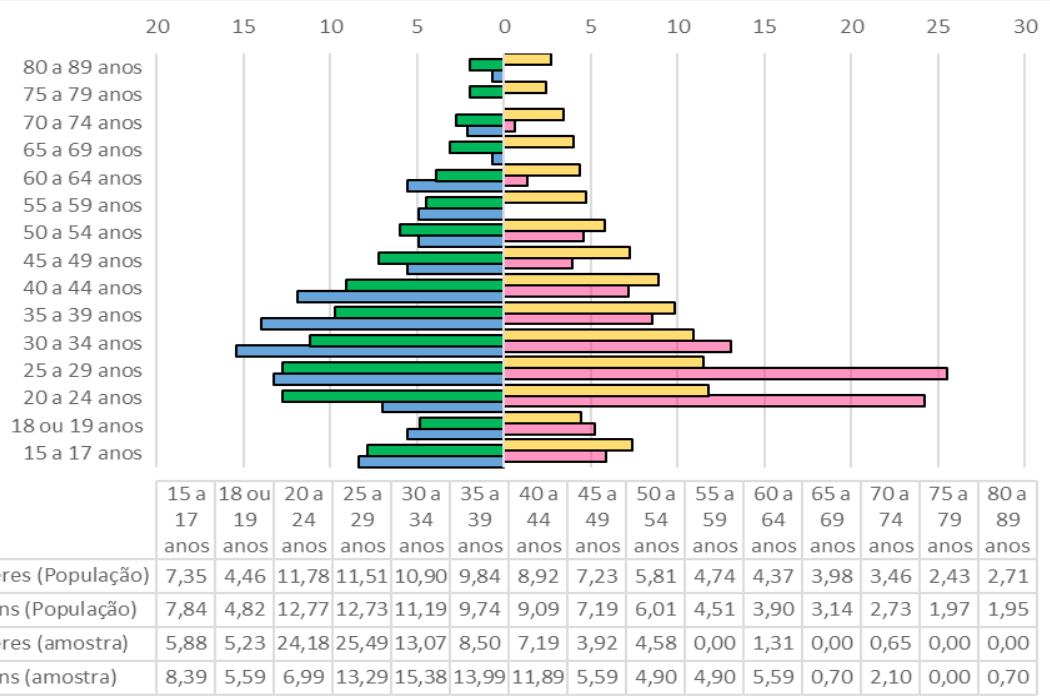

Fonte: os autores.

Gráfico 3 - Pirâmide etária em relação às resposas do item "Eu costumo doar alimentos a entidades carentes”

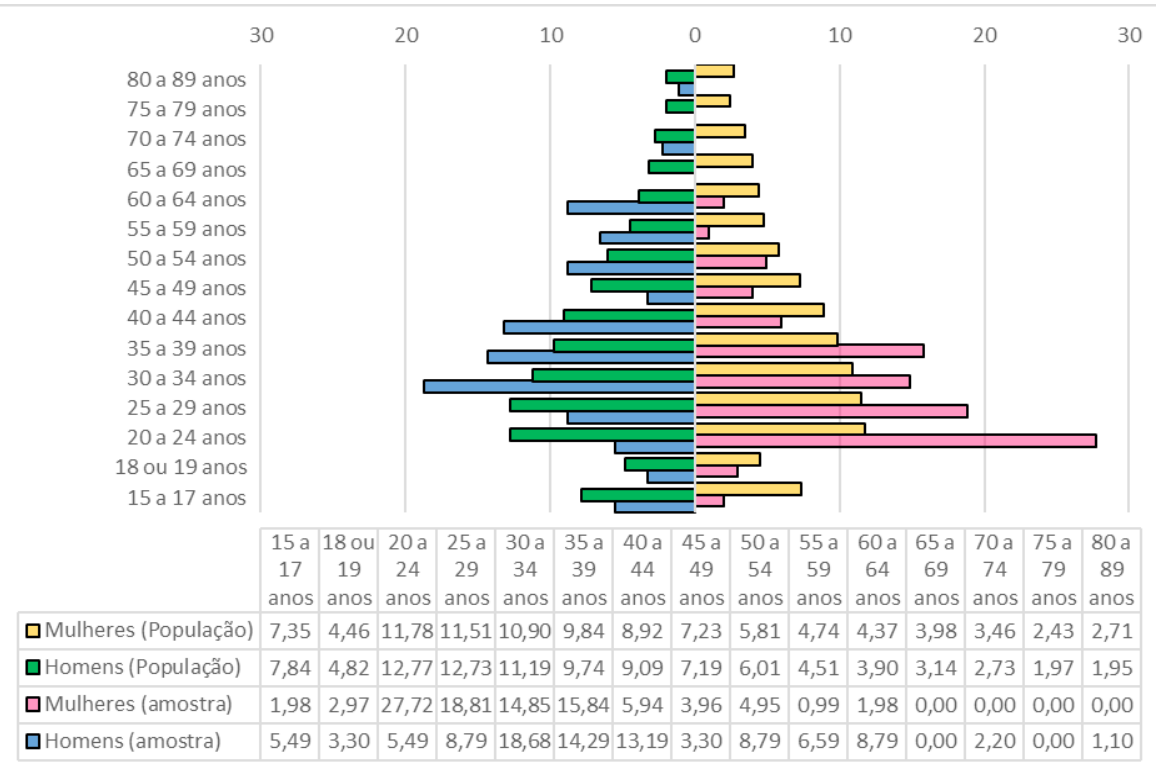

Fonte: os autores.

Entre as mulheres, o maior percentual de pessoas que auxiliam e que gostariam de auxiliar as entidades carentes (com alimentos ou não) encontra-se entre 20 e 
29 anos, como se observa nos Gráficos 1 e 2. Ressalta-se que essa faixa etária engloba maior parte das mulheres da Cidade de Guarabira, PB. Dessa forma, esse é um público que, caso incentivado, pode gerar grandes quantidades de doações. Já no que se refere à idade dos homens, os de maior idade apresentaram maior tendência (já doam ou gostariam de doar), porém, essa é uma parcela não tão significativa da população de Guarabira, PB.

Isolando as mulheres entre 20 e 29 anos, que responderam positivamente a questão “Eu gostaria de auxiliar entidades carentes”, percebeu-se que as que constituíram família (casadas ou que possuem união estável) apresentam maior interesse para realizar doações em relação às mulheres solteiras (79\% para as com família e 65,4\% para as solteiras), assim como gerariam maior quantitativo de doações, visto que as casadas constituem um quantitativo maior entre as pessoas que gostariam de auxiliar entidades carentes, equivalente a $51,3 \%$ do quesito.

As pirâmides etárias de pessoas que ajudam de alguma forma as entidades carentes (Gráfico 1) se apresentaram de forma similar às de quem auxilia com a doação de alimentos (Gráfico 3), isso porque 79,6\% das pessoas que afirmam auxiliar entidades carentes estariam doando alimentos (mesmo que não exclusivamente) e apenas 5,4\% delas afirmam auxiliar de alguma forma que não seja por meio de doação de alimentos. Tal fato ressalta a importância do desenvolvimento de estudos que comprovem, nas diversas realidades, a tendência de doação de alimentos, tanto pela evidente demanda por parte das entidades carentes quanto pela (também) evidente escassez de pesquisas nessa área, bem como o comprovado interesse nesse tipo de doação, por parte dos pesquisados.

O Gráfico 4 foi gerado para fins de analisar a forma de doação de alimentos para aqueles entrevistados interessados em doar, diante das opções: adquirir o alimento para doação (comprar) ou doar apenas aquele alimento que não utilizaria em casa (doar). 
Gráfico 4 - Pirâmide etária em relação às pessoas que gostariam de comprar alimentos para doar e pessoas que doariam os alimentos não consumidos em casa

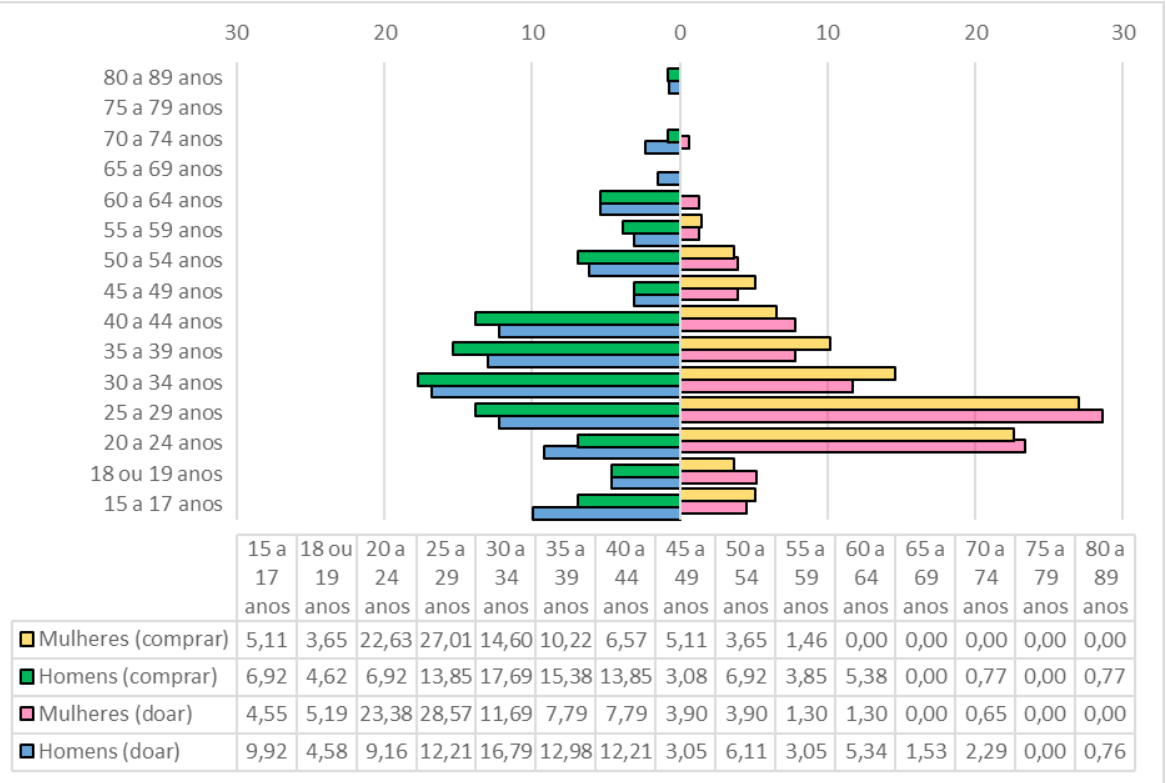

Fonte: os autores.

A análise do Gráfico 4 permite constatar que os homens dispostos a comprar para doar tendem a se concentrar em faixas etárias mais altas que as das mulheres. Nas faixas etárias entre 15 e 24 anos, os homens preferem doar aquilo que já possuem, provavelmente por ainda não possuírem autonomia financeira domiciliar para utilizar os recursos da família na compra de bens que serão destinados somente à doação. Em quase todas as demais faixas etárias, os homens preferem adquirir alimentos com destino certo para doação. Logo, a estratégia de estímulo à doação, para os homens, deve ser baseada nas sugestões de compra dos alimentos. Esse mesmo comportamento é visto para as mulheres mais jovens (até 29 anos), provavelmente em razão de a maioria das mulheres com interesse em comprar alimentos para doar (74\%) apresentarem um salário que não ultrapassa R\$1.500,00. Vale destacar que, entre as mulheres entre 20 e 29 anos, 30,8\% são mulheres que não auxiliam mas poderiam e gostariam de auxiliar via doação dos alimentos que venceriam em suas casas (representando $72,7 \%$ das que não doam), sendo esse um grande nicho de potenciais doadores para ser explorado.

Diante dos resultados expostos até o momento, tem-se importância de avaliar, em conjunto, dois aspectos socioeconômicos relevantes: o estado civil e a renda. 
Em relação ao estado civil, tem-se que todos os viúvos entrevistados afirmaram prestar auxílio a entidades carentes, com diferenças estatisticamente significantes dos demais (p-valor=0,000). Esses 71,4\% de doadores doam alimentos (28,6\% deles realizam algum outro tipo de doação). Vale destacar que apenas 57,1\% gostariam ou poderiam comprar para doar, enquanto 85,7\% doariam alimentos que não utilizariam em casa. Tem-se, assim, um grupo ativo no auxílio às entidades carentes, com preferência pela doação sem adquirir o produto. Destaca-se, entretanto, que parte significativa deles não realizam essas doações em forma de alimentos. O estímulo à doação, para esse público-alvo, deve ser focado em demonstrar o retorno social de tal prática, para além do custo financeiro.

Os divorciados, assim como os viúvos, destacam-se pelo interesse em realizar doações (94,7\%), e muito embora apenas 63,2\% destes efetivamente as concretizem, são o segundo grupo que mais auxilia entidades carentes. Tal fato sugere que pessoas que vivenciaram experiências de separação tendem a ser mais solidárias e empáticas que as demais. Nesse grupo, 57,9\% das pessoas costumam auxiliar doando alimentos. Porém, diferentemente dos viúvos, estas preferem comprar alimentos com destino à doação (78,9\%).

Ao separar os entrevistados casados e com união estável, observam-se resultados similares. A maioria deles afirmou que gostaria de auxiliar entidades carentes (81,3\% dos casados e 76,9\% que constituem união estável), e de fato, a maioria realmente as auxilia (56,3\% e 53,8\%, respectivamente). Destaca-se que foram apresentadas diferenças significativas estatisticamente entre os casados que doariam às entidades carentes, em comparação aos demais grupos (p-valor=0,021), revelando a importância deles frente aos demais no que se refere aos auxílios atualmente prestados a entidades carentes. Em ambos os casos, ainda, esse auxílio ocorreria por meio de alimentos (56,9\% e 56,4\%, respectivamente).

Os indivíduos casados preferem doar o que não consomem (78,1\%) em comparação em comprar para doar (73,8\%). Para os que estabeleceram união estável, o resultado é inverso, pois é preferível comprar para doar (69,2\%) em detrimento a doar o que já possuem mesmo que não irão consumir (64,1\%). Vale salientar que existe maior desperdício nos lares das pessoas casadas $(32,4 \%)$ que nos de pessoas com união estável (25,6\%), revelando que provavelmente as pessoas com união estável estão, atualmente, mais preocupadas em evitar o desperdício, de forma que, para realizarem doações de alimentos, provavelmente precisarão comprar para doar. Assim, embora ambos os grupos sejam similares em seu interesse de doar, sugere-se uma estratégia inversa em relação ao estímulo a doações de alimentos. 
Os solteiros constituem o único grupo cuja minoria presta auxílio a entidades carentes (40,9\% para auxílios em geral e 40,3\% para alimentos). A maioria deles ainda afirmou apresentar interesse em auxiliar entidades (71,1\%), contudo, especialmente quanto ao aspecto de compra de alimentos para doação seus resultados são significantemente diferentes (p-valor=0,021) e mais baixos (64,8\% dos solteiros e 72,9\% dos demais gostariam de comprar para doar) que os advindos dos demais grupos. Ressalta-se que 73\% dos solteiros gostariam de doar alimentos que venceriam em suas casas, dessa forma, para tal grupo, deve-se focar no estímulo em adquirir doações sob forma de alimentos que seriam desperdiçados. Quantitativamente, tal tipo de doação seria expressivo, visto que esse grupo é o que apresentou maior percentual, equivalente a 63,6\% de desperdício em casa.

Por fim, em relação à renda, existem diferenças significantes estatisticamente entre as distintas faixas quanto a ajudar entidades carentes ( $\mathrm{p}$-valor=0,003). Com o aumento da renda, um quantitativo maior de pessoas parece se tornar socialmente ativo, havendo apenas na última faixa de renda (acima de $\mathrm{R} \$ 6.000,00$ ) uma diminuição do percentual de doadores (percentuais aproximadamente iguais ao da renda mais baixa). Além de doarem menos que as outras categorias (apenas 40\%), ainda foi observado que, para a doação de alimentos, o quantitativo é ainda menor (20\%).

Embora a última faixa de renda doe menos, é ainda a que mais afirma apresentar interesse em doar (100\% afirmam interesse enquanto nas demais a média é aproximadamente 77\%), podendo-se supor que estas não o fariam por não saber como fazê-lo (nenhum afirmou efetivamente saber como realizar as doações) ou por apresentar um pior controle de gastos, estando em uma situação constante de medo de faltar capital.

Com o aumento das faixas de renda, os entrevistados apresentaram maior tendência em comprar para doar, com exceção da última faixa etária (novamente). Porém, a preferência em todas as faixas etárias ainda é doar o que já compram e não consomem, do que comprar unicamente para doar.

\section{CONCLUSÃO}

As entidades carentes são necessárias para cobrir os espaços não cobertos pelas políticas públicas, trazendo uma vida com dignidade a inúmeras pessoas que necessitam delas, contudo, estas precisam de gestão para operar com eficácia e maximizar o efeito de suas ações com a comunidade. O primeiro passo para tal é manter doadores atuais e, principalmente, atingir os potenciais. O objetivo com esta pesquisa 
foi, portanto, traçar o perfil dos doadores efetivos e potenciais das entidades carentes, com vistas a influenciar estratégias de marketing de estímulo a doações.

A partir da análise dos resultados, percebeu-se que os entrevistados são, em sua maioria, mulheres casadas, com renda aproximada entre um salário mínimo e R\$ 1.500,00 e idade média de 33 anos. Quanto ao envolvimento destas com entidades carentes, tem-se que a maioria ajuda de alguma forma ao menos uma entidade e realizaria doações sob forma de alimentos, estando ambos os aspectos relacionados, ou seja, pessoas mais socialmente ativas tenderiam a doar mais alimentos.

Existe, contudo, uma possibilidade de ampliação do número de doadores, dado que existe um quantitativo maior de pessoas interessadas em realizar doações em detrimento às pessoas que efetivamente doam, de forma a se perceber a necessidade de alcance destas para auxiliar as entidades carentes a ampliarem o recebimento de doações. Observou-se, ainda, que mais pessoas estariam interessadas em doar os alimentos que já têm e não utilizam do que comprar para realizar a doação, devendo esse nicho também ser explorado pelas iniciativas de marketing social.

Contrariando as pesquisas observadas em outros países, notou-se, em relação aos entrevistados guarabirenses, que os homens apresentam um maior interesse em auxiliar as entidades, provavelmente em razão de apresentarem maior renda. Porém, entre os indivíduos que não doam, as mulheres se mostraram mais interessadas em iniciar a prática da doação. Para o estímulo de novas doações, deve-se priorizar o público feminino que, inclusive, é maioria quantitativa, e, para garantir a continuidade de doações já existentes, o marketing deve ser focado no público masculino.

Existe uma relação positiva e significativa entre disposição de doar e faixa etária, contudo, uma vez que a quantidade de pessoas jovens é maior, tem-se que o maior número de doadores potenciais se encontra entre 20 e 40 anos. As mulheres jovens (entre 20 e 29 anos) devem ser incentivadas a iniciar a prática de doar, sendo mais fácil o convencimento das casadas ou com união estável. Nesse ponto, vale lembrar que elas já apresentam predisposição e capacidade para doar o que já possuem, e que a maioria que não doa atualmente possui capacidade e interesse para isso. Dessa forma, fica evidente que esse grupo constitui importante público-alvo para estratégias de marketing.

A relação entre faixa etária e disposição de doar poderia estar vinculada, ainda, ao estado civil, visto que viúvos e divorciados são os indivíduos com maiores percentuais de doadores, provavelmente por apresentarem maior experiência de vida e terem passado por situações pessoais (como perdas), confirmando os argumentos de Snipes e Oswald (2010), que estimulam o senso de solidariedade. O fato de os solteiros serem o único grupo cuja minoria de pessoas auxilia entidades carentes corrobora 
a explicação. Destaca-se, ainda, que os viúvos, casados e solteiros apresentam maior índice de desperdício em casa, quando analisados em conjunto, preferindo doar o que já possuem. Nesse ponto, sugere-se que o marketing social, para o estímulo a esses grupos, considere o possível receio dos indivíduos em doar alimentos próximos ao vencimento. Dessa forma, entende-se que a própria entidade carente deve assumir uma corresponsabilidade, por meio da gestão administrativa, de modo a priorizar o controle dos materiais provenientes das doações, garantindo que eles se encontrem em condições próprias para consumo. Ao mesmo tempo, é fundamental que essas ações de marketing social promovam o estímulo à realização de controle do estoque eficiente nos domicílios, evitando a perda e o desperdício de alimentos.

Por fim, no que se refere à renda, o aumento dela traz um acréscimo percentual de doadores (geral e de alimentos), exceto na categoria mais alta, que embora seja a com mais interesse em doar, ainda é a que menos doa (sobretudo alimentos). Dessa forma, para o alcance de doadores potenciais, deve-se focar, principalmente, nessa faixa de renda a partir de marketing informativo (dado que afirmam não saber como realizar doações) e de estímulo à solidariedade.

Para fins de trabalhos futuros, sugere-se continuidade nos estudos que visam entender com maior profundidade os doadores em potencial, com ênfase na doação de alimentos, tema pouco estudado na realidade brasileira.

\section{REFERÊNCIAS}

ASSOCIAÇÃO BRASILEIRA DAS ONGS. Disponível em: <http://www.abong.org. br>. Acesso em: 20 nov. 2005.

BORBA, C. P. et al. Ferramentas de comunicação em organizações não governamentais. Pretexto, Belo Horizonte, v. 13, n. 3, p. 44-71, set. 2012.

BROWN-KRUSE, J.; HUMMELS, D. Gender effects in laboratory publics goods contribution: Do individuals put their money where their mouth is? Journal of economic behavior and organization, [S.1.]: Elsevier, v. 22, i. 3, p. 255-67, dez. 1993.

ECKEL, C. C.; GROSSMAN, P. J. Differences in the economic decisions of men and women: experimental evidence. Handbook of experimental economics results, [S.1.]: Elsevier, v. 1, p. 509-19, 2008.

IBGE. IBGE cidades. 2016. Disponível em: <http://www.cidades.ibge.gov.br/xtras/ home.php>. Acesso em: 27 maio 2016. 
NOWELL, C.; TINKLER, S. The influence of gender on the provision of a public good. Journal Of Economic Behavior And Organization, USA, v. 25, p. 25-36, dez. 1994.

OLIVEIRA, P. R. P. de; BORGES, F. Q. Organizações Não Governamentais e Captação de Recursos diante de Novos Modelos de Cooperação. Pretexto, Belo Horizonte, v. 14, n. 3, p. 11-27, set. 2013.

PEIXOTO, M.; PINTO, H. S. Desperdício de Alimentos: questões socioambientais, econômicas e regulatórias. Brasília, DF: Núcleo de Estudos e Pesquisas: CONLEG: Senado Federal, 2016. (Boletim Legislativo n. 41, 2016). Disponível em: <www.senado.leg.br/ estudos>. Acesso em: 16 fev. 2016.

RECEITA ESTADUAL. Planilha de Empresas Cadastradas na Paraíba. 2015. Disponível em: <https://www3.receita.pb.gov.br/servirtual>. Acesso em: $28 \mathrm{dez}$. 2015.

ROESCH, S. Gestão de ONGs: rumo a uma agenda de pesquisas que contemple sua diversidade. Trabalhos EnANPAD. 2002. Disponível em: <http://www.anpad.org.br/ diversos/trabalhos/EnANPAD/enanpad_2002/GPG/2002_GPG969.pdf>. Acesso em: 30 maio 2016.

SANTOS, E. F.; SILVA, C. E. A influência das estratégias de marketing na captação de recursos para o Terceiro Setor. Revista Brasileira de Administração Científica, Aquidabã, v. 3, n. 1, p. 94-106, 2012.

SANTOS, G. E. de O. Cálculo amostral: calculadora on-line. Disponível em: <http://www.calculoamostral.vai.la>. Acesso em: 30 mar. 2016.

SCHNEIDER, F. The evolution of food donation with respect to waste prevention. Waste Management, [S.l.]: Elsevier, v. 33, i. 3, p. 755-763, mar. 2013.

SILVA, E. L. de; MENEZES, E. M. Metodologia da pesquisa e elaboração de dissertação. 4. ed. rev. e atual. Florianópolis: UFSC, 2005.

SNIPES, R. L.; OSWALD, Sharon L. Charitable giving to not-for-profit organizations: factors affecting donations to non-profit organizations. Innovative Marketing, USA, v. 6, p. 73-80, 2010. Disponível em: <http://businessperspectives.org/journals_free/im/2010/ im_en_2010_01_Snipes.pdf>.Acesso em: 29 maio 2016. 


\section{THIBES, M. M.; MORETTO NETO, L. Mobilização de Recursos nas Organizações}

da Sociedade Civil: um estudo de caso. Belo Horizonte: Pretexto, v. 12, n. 4, p. 133-155, dez. 2011.

TONDOLO, R. da R. P. Aspectos emergentes entre o terceiro setor e a inovação social: um olhar a partir do contexto brasileiro. Revista Brasileira de Gestão e Inovação, Caxias do Sul, v. 1, n. 1, p. 21-36, dez. 2013.

VERHAERT, G. A.; POEL, D. v. D. Empathy as added value in predicting donation behavior. Journal Of Business Research, [S.l.]: Elsevier, v. 64, n. 12, p. 1288-1295, dez. 2011.

VIDAL, F. A. B.; MENEZES, M. I. C. B. B. de. Gestão de ONGs e Desenvolvimento Social: paradoxos e desafios da Administração no Terceiro Setor. Trabalhos ENEO. 2004. Disponível em: <http://www.anpad.org.br/diversos/trabalhos/EnEO/eneo_2004/2004_ ENEO307.pdf>. Acesso em: 30 maio 2016.

\section{Como citar este artigo:}

\section{ABNT}

GOMES, Anna Cecília Chaves et al. Os doadores e potenciais doadores de entidades carentes: Quem são eles? RACE, Revista de Administração, Contabilidade e Economia, Joaçaba: Ed. Unoesc, v. 17, n. 1, p. 313-332, jan./abr. 2018. Disponível em: <http://editora.unoesc.edu.br/index.php/race>. Acesso em: dia/mês/ano.

\section{APA}

Gomes, A. C. C., Almeida, B. L. A. de, Lima, A. R. A. de, Santos, A. R. dos, Santos, J. J. dos, Nascimento, C. da S., Freire, A. C. C., Abreu, T. L. de. (2018). Os doadores e potenciais doadores de entidades carentes: Quem são eles? RACE, Revista de Administração, Contabilidade e Economia, 17(1), 313-332. Recuperado em dia/mês/ano, de http://editora.unoesc.edu.br/index.php/race 